\title{
Ready or Not: An Examination of Health and Educational Disparities through the Lens of a Social Determinants of Health Framework during Early Childhood
}

\author{
Roseanne L. Flores \\ Hunter College of the City University of New York, New York, USA \\ Email: rflores@hunter.cuny.edu
}

How to cite this paper: Flores, R. L. (2021). Ready or Not: An Examination of Health and Educational Disparities through the Lens of a Social Determinants of Health Framework during Early Childhood. Open Journal of Social Sciences, 9, 261-278. https://doi.org/10.4236/jss.2021.93018

Received: January 20, 2021

Accepted: March 19, 2021

Published: March 22, 2021

Copyright (อ 2021 by author(s) and Scientific Research Publishing Inc. This work is licensed under the Creative Commons Attribution International License (CC BY 4.0).

http://creativecommons.org/licenses/by/4.0/

\section{(c) (i) Open Access}

\begin{abstract}
Objective: African-American, Hispanic, and poor children are at the utmost risk of experiencing adverse health and educational outcomes. Research has demonstrated that health and education disparities occur within the context of social determinants of health. The purpose of this study was to examine the relationship between social determinants of health and health and educational disparities that begin early childhood. Methods: Using data from the 2011/ 2012 National Survey of Children's Health the sample for the current study included data for 1496 African-American and 2451 Hispanic children 3 - 5 years of age. Indicators of potential health and education disparities included measures of access to healthcare, measures of health and dental health, and measures of early childhood experiences. Results: The findings revealed that African-American, Hispanic, and poor children experienced more significant disparities in health and early childhood outcomes than their White and wealthier peers and that neighborhood risks were related to poorer health and educational outcomes. Conclusions: The results suggest that ensuring health equity and reducing health and educational disparities during early childhood can only occur by focusing on upstream determinants of health which include risk exposure, social disadvantage, and social inequities.
\end{abstract}

\section{Keywords}

Health Disparities, Early Childhood, Poverty, African-American and Hispanic Children, Social Determinants of Health, National Survey of Children's Health

\section{Introduction}

Today 1 in 6 children are growing up in poverty in the United States (Children's 
Defense Fund, n.d.). In 2018, 1 in 18 children were underinsured with poor children and children of color disproportionately represented within this group (Children's Defense Fund, n.d.). Moreover, in 2018 approximately thirty-three percent of individuals experiencing homelessness lived in families with children (Children's Defense Fund, n.d.). Children's healthy growth and development are dependent upon their biological, social, and physical environments. Where they live, play, and spend most of their waking hours is dependent upon the social, physical, mental, spiritual, and economic resources available to their parents (Crosnoe, Wu, \& Bonazzo, 2012; Woolf \& Braveman, 2011; Braveman, SadeghNobari, \& Egerter, 2011). Thus, children's health and well-being are linked to their parents' health and well-being (Braveman, Sadegh-Nobari, \& Egerter, 2011). For children growing up in well-to-do environments, the developmental outcomes are often quite promising; however, for those children with exposure to a more significant number of risks, the health outcomes are quite bleak (Aber, Bennett, Conley, \& Li, 1997). These children will carry the burden of disease within society.

In 2003, the Institute of Medicine produced a report entitled "Unequal Treatment: Confronting Racial Disparities in Health Care," which delineated the inequalities within the health care system that affected the health outcomes of specific populations, in particular African-Americans and Hispanics across the lifespan (Smedley, Stith, \& Nelson, 2003). These disparities outlined in the report have become known as health disparities and reflect the prevalence or burden of disease among marginalized groups.

Within the United States, health disparities are often reflected across race, SES, and gender. This report's findings demonstrated that African-Americans and Hispanics tended to receive lower-quality care and had access to more inferior services than their White peers, with minority patients having higher mortality rates (Smedley, Stith, \& Nelson, 2003). Thus the consequences are that minority patients tend to encounter more significant disparities in their health care which in turn lead to poorer health outcomes.

The question that arises then is what is leading to the disparities in health. Is it the lack of health insurance, lack of access to quality care, genetic makeup, or the neighborhood one lives in or some combination of them all? To understand the complexity involved in examining and assessing the causal pathways that lead to health disparities, one must begin to address the social determinants of health.

\subsection{Social Determinants of Health}

The social determinants of health are often thought of as social, economic, and environmental factors that affect health outcomes. These factors are often described as being upstream or downstream (Woolf \& Braveman, 2011; Braveman, Egerter, \& Williams, 2011; Bharmal et al., 2015). Upstream factors are those that set the causal pathways in motion, whereas the downstream factors are closer to the health outcomes. For example, a child who is consuming an over-abundance of sugar-sweetened and fatty foods, which may, in turn, lead to obesity, would be 
an example of a downstream determinant of health. In contrast, resources such as education, income, and neighborhoods with few or no grocery stores would fall under the category of an upstream social determinant of health.

In trying to address and reduce health disparities within an individual, it becomes critical to address the role of upstream determinants of health in the persistence of disease within those communities in which individual resides (Woolf \& Braveman, 2011; Braveman, Egerter, \& Williams, 2011). Furthermore, as we begin to understand how upstream determinants of health contribute to health disparities within specific populations, we need to be mindful of how they affect adult behavior and how they affect the health and well-being of children, as healthy behavior begins in childhood (Francis et al., 2018). To that end, we must start to examine the research that addresses the prevalence of health disparities within children and the connection between health disparities and the social determinants of health during the early years (Tolliver, 2010).

\subsection{Social Determinants of Health and Early Childhood}

The conditions under which children are born expose them to environments that can place them on a positive or negative life course (Moore, McDonald, Carlon, \& O'Rourke, 2015). To date, there has been a large body of research that has demonstrated that early life experiences can positively or negatively affect brain development, socio-emotional functioning, health, and early learning (Crosnoe, Wu, \& Bonazzo, 2012; Woolf \& Braveman, 2011; Braveman, Sadegh-Nobari, \& Egerter, 2011; Braveman, Egerter, \& Williams, 2011; Phillips \& Shonkoff, 2000). Young children are growing up in low-income households where social and economic resources are strained fare less well with respect to physical health, socio-emotional, cognitive, and behavioral developmental outcomes than their more affluent peers (Hertzman, 2010; Woolf \& Braveman, 2011). Moreover, AfricanAmerican and Hispanic children are often less likely to be in excellent or good health than their White peers, placing them at a disadvantage to develop into healthy adults (Flores, Olson, \& Tomany-Korman, 2005). Furthermore, it has also been demonstrated that health disparities are linked to school readiness (Currie, 2005). For example, children who experience chronic health problems such as untreated cavities are less likely to do well in school and often have behavior problems. These children are often from low-income families, with African-American and Hispanic toddler and preschool-aged children having more untreated dental cavities than their White peers (Currie, 2005). Thus, AfricanAmerican, Hispanic, and poor children are not only on a trajectory for experiencing poor health outcomes; they are also on course for having limited academic success, a foundation that will prove to be deleterious for positive adult growth and development (Currie, 2005).

Despite these outcomes, few studies have examined the relationship between disparities in health and early childhood experiences within the context of downstream and upstream social determinants of health, in particular, the health and early childhood experiences for African-American and Hispanic children living 
in poverty.

\subsection{Purpose of the Research}

In order to address this gap in the research, the purpose of the present study was to examine the association among access to healthcare, living in neighborhoods with exposure to multiple risk factors, and the educational and health outcomes for young African-American and Hispanic children. More specifically, the questions assessed were as follows: 1) What is the prevalence of access to health care, dental care, and mental healthcare for African-American and Hispanic children 3 - 5 years of age?; 2) What is the prevalence of parental concerns about receptive and expressive language, and the behavior of African-American and Hispanic 3 - 5-year-old children?; 3) What is the relationship between access to medical healthcare and living in neighborhoods with detracting elements and the overall health for African-American and Hispanic children 3 - 5 years of age?; 4) What is the relationship between access to medical health care and living in neighborhoods with detracting elements and the physical health of AfricanAmerican and Hispanic children 3 - 5 years of age?; 5) What is the relationship between access to dental healthcare and living in neighborhoods with detracting elements and the oral health for African-American and Hispanic young children 3 - 5 years of age?; and 6) What is the relationship between access to mental health care and living in neighborhoods with detracting elements and the behavioral health and educational outcomes for African-American and Hispanic children 3 - 5 years of age?

\section{Methods}

\subsection{Data Source and Design}

The data for this paper comes from the 2011/2012 National Survey of Children's Health. The NSCH is a national survey conducted via telephone in English and Spanish and provides a wide range of information about children's health and well-being. A total of 95,677 surveys were collected nationally for children between the ages of $0-17$ years. Survey results were weighed to represent the population of non-institutionalized children at the national and state levels ages 0 17. The survey is sponsored by the Maternal and Child Health Bureau of the US Department of Health and Human Services and the National Center for Health Statistics of the Center of Disease Control and Prevention (Child and Adolescent Health Measurement Initiative, 2012). The data is housed on the Data Resource Center for Child and Adolescent Health (DRC) which provides access to public data on the status of children's health and health-related services for children, youth and families. Further details about the survey can be found on the Data Resource webpage (DCR, n.d.).

\subsection{Participants}

The demographic data for the survey includes indictors for US children by age 
group, sex of the child, the race and ethnicity distribution of the child population, the level of the child's household income, and quality of the neighborhood. The sample for the current study included data for 1496 African-American and 2451 Hispanic children 3 - 5 years of age. See Table 1 for weighted and unweighted demographic data for the sample.

\subsection{Variables}

\subsubsection{Independent Variables}

The primary independent variables for the study were quality and access to healthcare.

\section{Measures of Healthcare Access and Quality}

Mental Health Care. Access to mental health care was measured using the following indicator: "Receipt of needed mental health treatment or counseling in the past 12 months" with possible responses including (a) needed but did not get mental health services or (b) needed \& received mental health services.

Dental Health Care. Access to dental care was measured using the following

Table 1. Demographic information for children ages 3 - 5 .

\begin{tabular}{|c|c|c|c|}
\hline Variables & Weighted Estimates & Unweighted Estimates & $\%$ of Total \\
\hline \multicolumn{4}{|l|}{ Racel Ethnicity } \\
\hline Hispanic & $3,116,483.433$ & 2451 & 25.8 \\
\hline White, non-Hispanic & $6,098,268.852$ & 9548 & 50.5 \\
\hline Black, non-Hispanic & $1,518,822.241$ & 1496 & 12.6 \\
\hline Multiracial/Other non-Hispanic & $1,349,441.450$ & 1982 & 11.2 \\
\hline \multicolumn{4}{|l|}{ Sex of Selected Child } \\
\hline Male & $6,371,873.931$ & 8140 & 50.9 \\
\hline Female & $6,131,606.632$ & 7757 & 49.0 \\
\hline Refused & 6225.566 & 13 & 0 \\
\hline \multicolumn{4}{|l|}{ Household Income (SCHIP $)$} \\
\hline $0 \%-199 \%$ FPL & $5,842,195.330$ & 5998 & 46.7 \\
\hline $200 \%-299 \%$ FPL & $2,101,247.634$ & 2548 & 16.8 \\
\hline $300 \%-399 \%$ FPL & $1,482,904.045$ & 2183 & 11.9 \\
\hline $400 \%-499 \%$ FPL & $3,083,359.121$ & 5181 & 24.6 \\
\hline \multicolumn{4}{|l|}{ Detracting Neighborhood Elements ${ }^{b}$} \\
\hline $\begin{array}{l}\text { No Detracting elements } \\
\text { in the neighborhood }\end{array}$ & $8,615,907.750$ & 11235 & 70.6 \\
\hline $\begin{array}{l}\text { Neighborhood has } 1 \\
\text { detracting element from the list }\end{array}$ & $2,192,234.427$ & 2707 & 18.0 \\
\hline $\begin{array}{l}\text { Neighborhood has } 2 \\
\text { detracting element from the list }\end{array}$ & $937,203.026$ & 1092 & 7.7 \\
\hline $\begin{array}{l}\text { Neighborhood has } 3 \\
\text { detracting element from the list }\end{array}$ & $465,573.394$ & 558 & 3.8 \\
\hline
\end{tabular}

aSCHIP Qualification; States have broad flexibility to set their SCHIP income eligibility levels; most states cover children up to 200 percent of the federal poverty level (FPL), which, in 2006, was equivalent to $\$ 2767$ in monthly income for a family of three. Children generally must be uninsured to qualify for SCHIP-funded coverage. $0 \%-99 \%=$ poverty level; $100 \%-199 \%=$ near poverty level; $>200 \%=$ non poverty level; ${ }^{b} \mathrm{De}-$ tracting elements consist of litter, poorly kept or run down housing, or vandalism/graffiti. 
question: "During the past 12 months/since [child's] birth, how many times did your child see a dentist for preventive dental care such as check-ups and dental cleanings?" with possible responses including (a) no preventive dental care visits or (b) one or more preventive dental care visits.

Medical Health Care. Access to medical care was measured using the following question: "During the past 12 months/since [child's] birth, how many times did your child seen a doctor, nurse, or other health care provider for preventive medical care such as a physical exam or well-child checkup?" with possible responses including (a) no preventive medical care visits or (b) one or more preventive medical care visits.

\subsubsection{Dependent Variables}

The primary outcomes of interest in this study were the child's overall physical and dental health and educational outcomes.

\section{Measures of Health and Dental Health}

Overall physical health. Physical health was measured using the following question: "In general, how would you describe your child's health?" with possible responses including (a) excellent/very good; (b) good; or (c) fair/poor.

Behavioral health. Behavioral health was measured using the following question: "Are you concerned a lot, a little, or not at all about how your child behaves?" with possible responses including (a) a lot; (b) a little; or (c) not at all.

Oral health. Oral health was measured using the following question: "How would you describe the condition of your child's teeth?" with possible responses including (a) excellent/very good condition; (b) good condition; or fair/poor condition.

\section{Measures of Early Childhood Experiences}

Early learning, behavior and development. Concerns about early learning, behavior and development were measured by the following question: "Do you have any concerns about [child's] learning, development, or behavior?" with possible responses including (a) yes or (b) no.

Receptive language. Concerns about receptive language were measured by the following question: "Are you concerned a lot, a little, or not at all about how your child understands what you say?" with possible responses including (a) a lot, (b) a little or (c) not at all.

Expressive language. Concerns about expressive language were measured by the following question: "Are you concerned a lot, a little, or not at all about how your child talks and makes speech sounds?" with possible responses including (a) a lot, (b) a little or (c) not at all.

Family Reading. Family members reading to child was measured using the following question: "During the past week, how many days did you or other family members read stories to the child?" with possible response including (a) no days; (b) 1 or 2 days; (c) 3 or 4 days; (d) 5 or 6 days; or (e) every day.

\subsubsection{Demographic Factors}

Demographic factors included child's age, race and gender, household income 
based on SCHIP, and quality of neighborhood. All factors were included in the analyses.

\subsection{Statistical Analysis}

Statistical analyses were performed using the SPSS Complex Survey Samples software. To account for the complex sampling design of the NSCH all estimates were weighted and adjusted in the analysis unless specified in the results. The survey weight represents the population of non-institutionalized children ages 0 - 17 nationally and in each state ( $\mathrm{NSCH}$, n.d.)

\section{Results}

Table 1 provides an overview of the characteristics for children ages 3 - 5 represented in the study with $25.8 \%$ identifying as Hispanic and $12.6 \%$ as Black. $46.7 \%$ of the children identified as living in households that were either poor or near poor with approximately $29.5 \%$ living in neighborhoods with 1 or more detracting elements.

\subsection{Prevalence of Overall Health and Access to Healthcare, Dental Care, and Mental Health Care}

Descriptive statistics were computed for children 3 - 5 years of age to assess their overall health and the prevalence of their access to healthcare, dental care, and mental health care. Table 2 provides estimates for the overall health of children 3 - 5 with the majority of children reporting to being in excellent or good health. That said the number of children reported to being in fair or poor health is highest among Black children at 5.4\% and Hispanic children at $4.9 \%$.

Table 3 provides estimates describing the overall condition of 3 - 5 year old

Table 2. Overall health for children ages 3 - 5 by race.

\begin{tabular}{cccc}
\hline Variables & Weighted Estimates & Unweighted Estimates & \% of Total \\
\hline Excellent/ Very Good & & & \\
Hispanic & $2,325,236.599$ & 1915 & 74.6 \\
White, non-Hispanic & $5,617,632.829$ & 8861 & 92.1 \\
Black, non-Hispanic & $1,254,923.798$ & 1253 & 82.6 \\
Multiracial/Other non-Hispanic & $1,113,247.569$ & 1731 & 82.5 \\
Good & & & 20.5 \\
Hispanic & & 422 & 6.5 \\
White, non-Hispanic & $637,917.663$ & 539 & 12.0 \\
Black, non-Hispanic & $394,759.039$ & 193 & 14.8 \\
Multiracial/Other non-Hispanic & $182,321.827$ & 214 & \\
Fair/Poor & $200,185.752$ & & \\
Hispanic & & 113 & 4.9 \\
Multiracial/Other non-Hispanic & $360,008.129$ & 50 & 5.4 \\
Black, non-Hispanic & $85,176.615$ & 37 & 2.7 \\
\hline
\end{tabular}


Table 3. Condition of teeth for children ages 3 - 5 by race.

\begin{tabular}{cccc}
\hline Variables & Weighted Estimates & Unweighted Estimates & \% of Total \\
\hline Excellent/ Very Good & & & \\
Hispanic & $1,776,740.855$ & 1614 & 57.0 \\
White, non-Hispanic & $5,150,924.895$ & 8191 & 84.5 \\
Black, non-Hispanic & $1,137,431.410$ & 1160 & 74.9 \\
Multiracial/Other non-Hispanic & $1,010,813.334$ & 1500 & 74.9 \\
Good & & & \\
Hispanic & & & 29.5 \\
White, non-Hispanic & $918,902.438$ & 583 & 11.7 \\
Black, non-Hispanic & $281,194.404$ & 1057 & 18.5 \\
Multiracial/Other non-Hispanic & $253,549.639$ & 268 & 18.8 \\
Fair/Poor & & 348 & \\
Hispanic & & & 13.5 \\
White, non-Hispanic & $233,639.418$ & 251 & 3.8 \\
Black, non-Hispanic & $99,671.387$ & 67 & 6.6 \\
Multiracial/Other non-Hispanic & $84,953.881$ & 132 & 6.3 \\
\hline
\end{tabular}

children's teeth. In general the majority of children were reported to have teeth that are in excellent, very good, or good condition. The number of children reported to have teeth in fair or poor conditions was highest among Hispanics $13.5 \%$ children and Black children $6.6 \%$.

Table 4 provides estimates for access to preventative medical care for children during the past 12 months. In general the majority of children had access to 1 or more visits in the past 12 month. Among the children reported to having no preventative visits lack of preventive care was highest for Hispanic children at $16.4 \%$ and Black children at $12.3 \%$.

Table 5 provides estimates for access to preventative dental care for children during the past 12 months. In general the majority of children were reported to have had access to 1 or more preventative visits in the past 12 month. Among the children reported to having no preventative visits lack of preventative care was highest for Black children $30.3 \%$ and White children at $27.8 \%$.

Table 6 provides estimates for access to mental health care by children during the past 12 months. In general the majority of children were reported that they needed treatment or counseling but did not receive it with Hispanic and Black children reporting the highest need for care $67.4 \%$ and 61.7 respectively, but not receiving it.

\subsection{Prevalence of Parental Concerns about Children's Receptive and Expressive Language and Learning, Development and Behavior}

Table 7 provides estimates for parent's expression of concern over the ability of their children to understand language. Hispanic and White parents expressed more concern about their children's abilities with African-American parents expressing less concern. 
Table 4. Preventative medical care for children ages 3 - 5 by race.

\begin{tabular}{cccc}
\hline Variables & Weighted Estimates & Unweighted Estimates & \% of Total \\
\hline Preventative Medical Care & & & \\
No preventive visits during past & & & \\
12 months & & & \\
Hispanic & $509,002.913$ & 366 & 16.4 \\
White, non-Hispanic & $514,189.965$ & 865 & 8.5 \\
Black, non-Hispanic & $182,790.172$ & 159 & 12.3 \\
Multiracial/Other non-Hispanic & $157,196.040$ & 249 & \\
1 or more visits during past 12 & & & \\
months & & & 83.6 \\
Hispanic & & & \\
White, non-Hispanic & $5,559,113.448$ & 2061 & 81.5 \\
Black, non-Hispanic & $1,301,671.882$ & 1315 & 88.3 \\
Multiracial/Other non-Hispanic & $1,184,403.438$ & 1715 & \\
\hline
\end{tabular}

Table 5. Preventative dental care for children ages 3 - 5 by race.

\begin{tabular}{cccc}
\hline Variables & Weighted Estimates & Unweighted Estimates & \% of Total \\
\hline Preventative Dental Care & & & \\
No preventive visits during past & & & \\
12 months & & 655 & 24.6 \\
Hispanic & $765,288.583$ & 2469 & 30.3 \\
White, non-Hispanic & $1,692,432.891$ & 343 & 33.5 \\
Black, non-Hispanic & $459,964.771$ & 594 & \\
Multiracial/Other non-Hispanic & $448,596.112$ & & 75.4 \\
1 or more visits during past 12 & & & 72.2 \\
months & & 1792 & 69.7 \\
Hispanic & $2,349,770.803$ & 7059 & 66.5 \\
Bhite, non-Hispanic & $4,396,747.324$ & 1149 & 1376 \\
Bultiracial/Other non-Hispanic & $891,122.924$ & & \\
\hline
\end{tabular}

Table 6. Access to mental health care (past 12 months) for children ages 3 - 5 by race.

\begin{tabular}{cccc}
\hline Variables & Weighted Estimates & Unweighted Estimates & \% of Total \\
\hline $\begin{array}{c}\text { Access to Mental Health Care } \\
\text { (Past 12 Months) }\end{array}$ & & & \\
Needed and DID NOT & & & \\
get any mental health & & 76 & \\
tx/ counseling & & 210 & 67.4 \\
Hispanic & $119,748.083$ & 55 & 61.7 \\
White, non-Hispanic & $123,824.651$ & 57 & 45.9 \\
Black, non-Hispanic & $59,383.544$ & & \\
Multiracial/Other non-Hispanic & $35,178.096$ & & \\
\hline
\end{tabular}




\section{Continued}

\begin{tabular}{cccc}
\hline $\begin{array}{c}\text { Needed and received mental } \\
\text { health } \text { tx/ or counseling }\end{array}$ & & & \\
Hispanic & $57,956.650$ & 60 & 32.6 \\
White, non-Hispanic & $153,528.468$ & 200 & 55.4 \\
Black, non-Hispanic & $36,797.483$ & 37 & 38.3 \\
Multiracial/Other non-Hispanic & $41,444.256$ & 59 & 54.1 \\
\hline
\end{tabular}

Table 7. Parental concerns about receptive language for children ages 3 - 5 .

\begin{tabular}{|c|c|c|c|}
\hline Variables & Weighted Estimates & Unweighted Estimates & $\%$ of Total \\
\hline \multicolumn{4}{|c|}{ Race and Ethnicity Categories } \\
\hline \multicolumn{4}{|l|}{ Hispanic } \\
\hline (A Lot) & $322,553.495$ & 198 & 2.7 \\
\hline (A little) & $383,047.855$ & 273 & 3.2 \\
\hline (Not at All) & $2,406,314.447$ & 1971 & 19.9 \\
\hline \multicolumn{4}{|c|}{ White, non-Hispanic } \\
\hline (A Lot) & $181,332.220$ & 235 & 1.5 \\
\hline (A little) & $380,747.476$ & 492 & 3.2 \\
\hline (Not at All) & $5,532,746.980$ & 8812 & 45.8 \\
\hline \multicolumn{4}{|c|}{ Black, non-Hispanic } \\
\hline (A Lot) & $134,999.687$ & 141 & 1.1 \\
\hline (A little) & $145,690.147$ & 153 & 1.2 \\
\hline (Not at All) & $1,238,132.406$ & 1202 & 10.2 \\
\hline \multicolumn{4}{|c|}{ Multiracial/Other non-Hispanic } \\
\hline (A Lot) & $97,835.414$ & 112 & 0.8 \\
\hline (A little) & $133,480.108$ & 171 & 1.1 \\
\hline (Not at All) & $1,117,876.935$ & 1698 & 9.3 \\
\hline
\end{tabular}

Table 8 displays the estimates for parent's expression of concern over the ability of their children to make speech sounds and expressive themselves. Again White and Hispanic parents expressed more concern about their children's abilities to express themselves than African-American parents who expressed less concern.

Table 9 presents the estimates for parent's expression of concern about the learning, development, or behavior of their 3 - 5 year old children. White and Hispanic parents expressed more concern about their children's learning, development, and behavior than African-American parents who expressed less concern.

\subsection{Upstream and Downstream Determinants of Health and Child Outcomes}

\subsubsection{Access to Medical Healthcare and Neighborhood Characteristics and Overall Health}

Ordinal regression analysis was conducted adjusting for age, race, gender, and income to examine the relationship between access to healthcare and the overall 
Table 8. Parental concerns about use of expressive language for children ages 3 - 5.

\begin{tabular}{cccc}
\hline Variables & Weighted Estimates & Unweighted Estimates & $\%$ of Total \\
\hline Race and Ethnicity Categories & & & \\
Hispanic & & & \\
(A Lot) & $316,879.619$ & 187 & 2.6 \\
(A little) & $501,092.393$ & 1882 & 4.1 \\
(Not at All) & $2,296,886.974$ & & 19.0 \\
& & & \\
White, non-Hispanic & & 399 & 2.4 \\
(A Lot) & $286,625.683$ & 1381 & 7.9 \\
(A little) & $954,070.438$ & 7764 & 40.2 \\
(Not at All) & $4,857,323.085$ & & 1.2 \\
& & 144 & 2.0 \\
Black, non-Hispanic & & 253 & 9.4 \\
(A Lot) & $146,318.842$ & 1097 & \\
(A little) & $240,282.914$ & & 1.1 \\
(Not at All) & $1,131,766.629$ & & 1.8 \\
& & 146 & 8.3 \\
\hline Multiracial/Other non-Hispanic & & 295 & \\
(A Lot) & $128,723.027$ & 1539 & \\
(A little) & $216,882.092$ & & \\
(Not at All) & $1,003,490.044$ & & \\
\hline
\end{tabular}

Table 9. Parental concerns about learning, behavior and development for children ages 3 -5 .

\begin{tabular}{cccc}
\hline Variables & Weighted Estimates & Unweighted Estimates & \% of Total \\
\hline Race/ Ethnicity Categories & & & \\
Hispanic & & & \\
(No) & $2,664,064.473$ & 2120 & 22.1 \\
(Yes) & $446,343.342$ & 325 & 3.7 \\
& & & \\
White, non-Hispanic & & 8717 & 45.9 \\
(No) & $5,549,253.651$ & 824 & 4.5 \\
(Yes) & $547,008.145$ & & 11.1 \\
African American/Black & & 1310 & 1.4 \\
(No) & $1,346,562.079$ & 184 & \\
(Yes) & $171,279.231$ & & 1.4 \\
Multiracial/Other non-Hispanic & & 1774 & \\
(No) & $1,163,850.375$ & 204 & \\
(Yes) & $174,508.035$ & & \\
\hline
\end{tabular}

health of children. The odds ratio of 1.007 [95\% CI: 0.886, 1.145] indicates that the cumulative odds for children having 1 or more preventative medical visits are 1.007 times the cumulative odds of not receiving preventative health visits during the past 12 months (Table 10).

Ordinal regression analysis adjusting for age, race, gender, and income examining the association between neighborhood detractors and the overall health of children revealed positive associations for living in neighborhoods with no detracting elements vs 3 detracting elements 1.169 [95\% CI: 0.948, 0.1441], living 
Table 10. Ordinal regression predicting overall health.

\begin{tabular}{|c|c|c|c|}
\hline \multirow{2}{*}{ Predictor } & \multirow{2}{*}{ Cumulative Odds Ratio $^{\mathrm{a}}$} & \multicolumn{2}{|c|}{$95 \%$ CI } \\
\hline & & Lower & Upper \\
\hline \multicolumn{4}{|l|}{ Access to Health Care } \\
\hline $\begin{array}{l}\text { Needed } 1 \text { or more preventative } \\
\text { healthcare visits vs. no preventative } \\
\text { visits in the last } 12 \text { months }\end{array}$ & 1.007 & 0.886 & 1.145 \\
\hline \multicolumn{4}{|l|}{ Neighborhood Detractors ${ }^{b}$} \\
\hline $\begin{array}{c}\text { No detracting elements vs. Neighborhood } \\
\text { has } 3 \text { detracting elements }\end{array}$ & 1.169 & 0.948 & 1.441 \\
\hline Neighborhood has 1 detracting element & 1.071 & 0.853 & 1.346 \\
\hline Neighborhood has 2 detracting elements & 1.068 & 0.813 & 1.403 \\
\hline
\end{tabular}

in neighborhoods with 1 vs 3 detracting elements 1.071 [95\% CI: $0.853,1.346$ ] and living in neighborhoods with 2 vs 3 detracting elements 1.068 [95\% CI: $0.813,1.403$ ] (Table 10).

\subsubsection{Access to Dental Care and Neighborhood Characteristics and Overall Dental Health}

Table 11 provides the ordinal regression results examining the relationship between access to dental care and the overall dental health for children. The odds ratio of 0.696 [95\% CI: $0.628,0.772$ ] indicates that the cumulative odds for having no preventative visits during the past 12 months was 0.696 the odds of having 1 or more visits during the past 12 months.

Ordinal regression analysis adjusting for age, race, gender, and income examining the association between neighborhood detractors and the overall dental health of children revealed positive associations for living in neighborhoods with no detracting elements vs 3 detracting elements 1.164 [95\% CI: 0.979, 1384], living in neighborhoods with 1 vs 3 detracting elements 1.050 [95\% CI: 0.869, 1.268] and living in neighborhoods with 2 vs 3 detracting elements 1.068 [95\% CI: $0.742,1.140]$ (Table 11).

\subsubsection{Access to Mental Health Care and Neighborhood Characteristics and Behavioral Health}

Table 12 presents the overall associations between access to mental health care and behavioral health. The odds ratio of 0.882 [95\% CI: $0.480,1.62]$ indicates that the cumulative odds for children needing but not receiving any mental health treatment vs needing and not receiving mental health treatment are 0.882 times the cumulative odds of not receiving any mental health treatment.

Ordinal regression analysis adjusting for age, race, gender, and income examining the association between neighborhood detractors and the behavioral health of children revealed positive associations for living in neighborhoods with no detracting elements vs 3 detracting elements 2.102 [95\% CI: 1.275, 3.466], 
Table 11. Ordinal regression predicting dental health.

\begin{tabular}{cccc}
\hline & & \multicolumn{2}{c}{$95 \%$ CI } \\
\cline { 3 - 4 } Predictor & Cumulative Odds Ratio ${ }^{\mathrm{a}}$ & Lower & Upper \\
\hline $\begin{array}{c}\text { Access to Dental Care } \\
\text { No preventative visits during } \\
\text { past 12 months vs 1 or more } \\
\text { visits in the last 12 months }\end{array}$ & 0.696 & 0.886 & 1.145 \\
$\quad$ Neighborhood Detractors & & & \\
No detracting elements vs. Neighborhood & & & \\
$\quad$ has 3 detracting elements & 1.164 & 0.979 & 1.384 \\
$\begin{array}{c}\text { Neighborhood has 1 detracting element } \\
\text { Neighborhood has 2 detracting elements }\end{array}$ & 1.050 & 0.869 & 1.268 \\
\hline
\end{tabular}

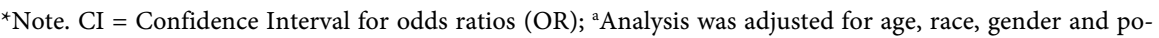
verty on SCHIP; betracting elements consist of litter, poorly kept or rundown housing, or vandalism/graffiti.

Table 12. Ordinal regression predicting behavioral health.

\begin{tabular}{|c|c|c|c|}
\hline \multirow{2}{*}{ Predictor } & \multirow{2}{*}{ Cumulative Odds Ratio $^{a}$} & \multicolumn{2}{|c|}{$95 \%$ CI } \\
\hline & & Lower & Upper \\
\hline \multicolumn{4}{|l|}{ Access to Mental Health } \\
\hline $\begin{array}{l}\text { Needed and did not receive any mental } \\
\text { health treatment vs needed and received } \\
\text { mental health treatment }\end{array}$ & 0.882 & 0.480 & 1.621 \\
\hline \multicolumn{4}{|l|}{ Neighborhood Detractors $^{b}$} \\
\hline $\begin{array}{c}\text { No detracting elements vs. Neighborhood } \\
\text { has } 3 \text { detracting elements }\end{array}$ & 2.102 & 1.275 & 3.466 \\
\hline Neighborhood has 1 detracting element & 1.978 & 1.135 & 3.448 \\
\hline Neighborhood has 2 detracting elements & 1.243 & 0.680 & 2.270 \\
\hline
\end{tabular}

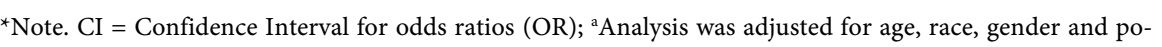
verty on SCHIP; 'Detracting elements consist of litter, poorly kept or rundown housing, or vandalism/graffiti.

living in neighborhoods with 1 vs 3 detracting elements 1.978 [95\% CI: 1.135, 3.448] and living in neighborhoods with 2 vs 3 detracting elements 1.243 [95\% CI: 0.680, 2.270] (Table 12).

\subsubsection{Access to Mental Health Care and Neighborhood Characteristics and Educational Outcomes}

\section{Expressive Language}

Table 13 provides the overall association between access to mental health care and a parent's concerns about their child being able to produce speech sounds. The odds ratio of 1.272 [95\% CI: $0.753,2.149$ ] indicates that the cumulative odds for children needing but not receiving any mental health treatment vs needing and not receiving mental health treatment are 1.272 times the cumulative odds of not receiving any mental health treatment.

Ordinal regression analysis adjusting for age, race, gender, and income examining the association between neighborhood detractors and the expressive 
language of children revealed positive associations for living in neighborhoods with no detracting elements vs 3 detracting elements 0.865 [95\% CI: 0.555, 1.348], living in neighborhoods with 1 vs 3 detracting elements 0.936 [95\% CI: $0.580,1.510$ ] and living in neighborhoods with 2 vs 3 detracting elements 1.304 [95\% CI: 0.771, 2.205] (Table 13).

\section{Receptive Language}

Table 14 reports the association between access to mental health care and a parent's concerns about their child being able to understand language. The odds ratio of 1.104 [95\% CI: $0.640,1.904$ ] indicates that the cumulative odds for children needing but not receiving any mental health treatment vs needing and not receiving mental health treatment are 1.104 times the cumulative odds of not receiving any mental health treatment.

Ordinal regression analysis adjusting for age, race, gender, and income examining the association between neighborhood detractors and the expressive

Table 13. Ordinal regression predicting expressive language.

\begin{tabular}{|c|c|c|c|}
\hline \multirow{2}{*}{ Predictor } & \multirow{2}{*}{ Cumulative Odds Ratio ${ }^{\mathrm{a}}$} & \multicolumn{2}{|c|}{$95 \% \mathrm{CI}$} \\
\hline & & Lower & Upper \\
\hline \multicolumn{4}{|l|}{ Access to Mental Health } \\
\hline $\begin{array}{l}\text { Needed and did not receive any mental } \\
\text { health treatment vs needed and received } \\
\text { mental health treatment }\end{array}$ & 1.272 & 0.753 & 2.149 \\
\hline \multicolumn{4}{|l|}{ Neighborhood Detractors ${ }^{b}$} \\
\hline $\begin{array}{c}\text { No detracting elements vs. Neighborhood } \\
\text { has } 3 \text { detracting elements }\end{array}$ & 0.865 & 0.555 & 1.348 \\
\hline Neighborhood has 1 detracting element & 0.936 & 0.580 & 1.510 \\
\hline Neighborhood has 2 detracting elements & 1.304 & 0.771 & 2.205 \\
\hline
\end{tabular}

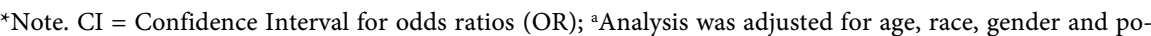
verty on SCHIP; 'betracting elements consist of litter, poorly kept or rundown housing, or vandalism/graffiti.

Table 14. Ordinal regression predicting receptive language.

\begin{tabular}{|c|c|c|c|}
\hline \multirow{2}{*}{ Predictor } & \multirow{2}{*}{ Cumulative Odds Ratio ${ }^{a}$} & \multicolumn{2}{|c|}{$95 \% \mathrm{CI}$} \\
\hline & & Lower & Upper \\
\hline \multicolumn{4}{|l|}{ Mental Health } \\
\hline $\begin{array}{l}\text { Needed and did not receive any mental } \\
\text { health treatment vs needed and received } \\
\text { mental health treatment }\end{array}$ & 1.104 & 0.640 & 1.904 \\
\hline \multicolumn{4}{|l|}{ Neighborhood Detractors ${ }^{b}$} \\
\hline $\begin{array}{c}\text { No detracting elements vs. Neighborhood } \\
\text { has } 3 \text { detracting elements }\end{array}$ & 0.972 & 0.628 & 1.505 \\
\hline Neighborhood has 1 detracting element & 0.870 & 0.540 & 1.401 \\
\hline Neighborhood has 2 detracting elements & 1.221 & 0.772 & 2.063 \\
\hline
\end{tabular}

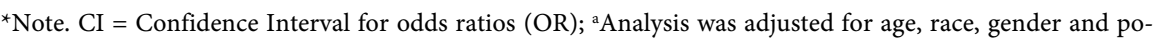
verty on SCHIP; 'betracting elements consist of litter, poorly kept or rundown housing, or vandalism/graffiti. 
language of children revealed positive associations for living in neighborhoods with no detracting elements vs 3 detracting elements 0.972 [95\% CI: 0.628, 1.505], living in neighborhoods with 1 vs 3 detracting elements 0.870 [95\% CI: $0.540,1.401]$ and living in neighborhoods with 2 vs 3 detracting elements 1.221 [95\% CI: 0.772, 2.063] (Table 14).

\section{Discussion}

The present study identified several upstream determinants of health, income, quality of the neighborhood, and income as a function of education, which provided the context for examining the health and early childhood experiences of a national sample of children 0 - 5 years of age. The findings from this study suggest that the burden of health disparities and early childhood experiences are borne by African-American, Hispanic, other minority, and poor children living in communities that are also bearing the brunt of inequalities.

It has been suggested that the upstream social determinants of health provide the ecological context for understanding the causal pathway that leads to health outcomes expressed within the downstream determinants, such as poor oral health (Woolf \& Braveman, 2011; Braveman, Egerter, \& Williams, 2011). The findings from this study, although not causally linked, provide evidence for this conceptual model.

When examining the conceptual framework developed by the Robert Wood Johnson (Braveman, Egerter, \& Williams, 2011), it becomes clear that economic, social opportunities and access to resources are the upstream causal mechanisms that influence individuals' behaviors in communities. This paper's findings suggest that African-American, Hispanic, other minority, and poor children live in households and communities that have access to fewer financial, educational, and social resources.

More of these children reside in working-poor households and live in homes where the primary language is not English and have fewer opportunities for positive early childhood experiences.

When examining the findings that address the access to, and quality of healthcare received by families the results suggests that African-Americans, Hispanics, other minority, and poor children are faring less well than their White and affluent peers with respect to: receiving preventative medical and dental care, having access to mental health care services, having one or more of their needs not met by the healthcare providers, experiencing frustration when trying to obtain a health care services for their children, having access to doctors who appear to be interested in discussing their concerns about their children's development, having children with poorer overall physical and dental health, and having more children with chronic health problems.

It should be noted, however, that while parents are reporting dissatisfaction concerning having one or more of their needs not met, the most significant disparity appears to occur in families with the $100 \%$ - 199\% FPL, indicating the 
poorest families are having their needs met through health care services provided by the government.

When examining the quality of early childhood experiences, African-American, Hispanic, other minority, and poor children are once again bearing the burden of poorer cognitive, linguistic, socio-emotional, and learning outcomes. These parents reported having more significant concerns about their children's learning development or behavior, the expressive and receptive language development of their children, the development of school-based skills of their children, and the resilience of their children. Furthermore, these families are spending less time reading to their children than their White and affluent peers, a factor which has been shown to predictive of later school success (Hart \& Risley, 1995).

In short, the same families who are living in communities that have limited access to physical, social, and financial resources are the same children who are experiencing greater disparities in health and early educational experiences, strongly suggesting that the upstream determinants of health are linked to the health and educational outcomes of children.

\section{Limitations of the Study}

It should be noted that while the findings from this research provide new knowledge that will move the field forward concerning our understanding of how upstream determinants of health may be linked to health disparities, there are nevertheless some limitations to the study. First, this study's findings do not define a causal pathway but rather provide information that will allow the field to begin to connect the dots between social determinants of health and early childhood developmental outcomes (Braveman, Egerter, \& Williams, 2011). Second, the data from this study do not consider all of the factors that may have affected the health and early education experiences of children, such as the discrimination and stress experienced directly or indirectly by their parents, thereby suggesting other pathways that might lead to poor developmental outcomes. That said, despite these limitations, this study provides an initial response to the call for more studies to examine health disparities within the context of upstream social determinants and early childhood (Braveman, Egerter, \& Williams, 2011).

\section{Conclusion}

The findings from this study support previous evidence that has demonstrated a critical relationship between social and economic factors and health and educational outcomes for young children (Currie, 2005; Chen, Martin, \& Matthews, 2006). Both the health measures and early childhood experience measures demonstrate that African-American, Hispanic, other minority and poor children are experiencing poorer health and educational outcomes than their White and more affluent peers, leaving them ill-prepared to lead healthy and productive lives. Moving forward, if we intend to shift the needle to reach health and educational equity for all, it will become imperative for scientists to develop more 
complex research designs that will address the complexity of development; practitioners to engage in practices that address the integration of needs within the whole child; and policymakers to develop more comprehensive approaches that will begin to address the upstream social determinants of health which are the cause for many of the poor health and early childhood outcomes for AfricanAmerican, Hispanic, minority, and poor children. Doing anything less will ensure health and education inequities persist across the lifespan.

\section{Conflicts of Interest}

The author declares no conflicts of interest regarding the publication of this paper.

\section{References}

Aber, J. L., Bennett, N. G., Conley, D. C., \& Li, J. (1997). The Effects of Poverty on Child Health and Development. Annual Review of Public Health, 18, 463-483. https://doi.org/10.1146/annurev.publhealth.18.1.463

Bharmal, N., Derose, K. P., Felician, M., \& Weden, M. M. (2015). Understanding the Upstream Social Determinants of Health (pp. 1-18). California: RAND.

Braveman, P., Egerter, S., \& Williams, D. R. (2011). The Social Determinants of Health: Coming of Age. Annual Review of Public Health, 32, 381-398. https://doi.org/10.1146/annurev-publhealth-031210-101218

Braveman, P., Sadegh-Nobari, T., \& Egerter, S. (2011). Early Childhood Experiences and Health (Issue Brief No. 2). Robert Wood Johnson Foundation: Author.

Chen, E., Martin, A. D., \& Matthews, K. A. (2006). Understanding Health Disparities: The Role of Race and Socioeconomic Status in Children's Health. American Journal of Public Health, 96, 702. https://doi.org/10.2105/AJPH.2004.048124

Child and Adolescent Health Measurement Initiative (2012). Fast Facts: 2011/12 National Survey of Children's Health. Data Resource Center, Supported by Cooperative Agreement 1-U59-MC06980-01 from the U.S. Department of Health and Human Services, Health Resources and Services Administration (HRSA), Maternal and Child Health Bureau (MCHB). http://www.childhealthdata.org

Children's Defense Fund (n.d.). The State of America's Children 2020.

https://www.childrensdefense.org/the-state-of-americas-children-2020

Crosnoe, R., Wu, N., \& Bonazzo, C. (2012). Child Health and Early Education. In V. Maholmes, \& R. B. King (Eds.), The Oxford Handbook of Poverty and Child Development (pp. 338-353). New York: Oxford University Press.

https://doi.org/10.1093/oxfordhb/9780199769100.013.0019

Currie, J. M. (2005). Health Disparities and Gaps in School Readiness. The Future of Children, 15, 117-138. https://doi.org/10.1353/foc.2005.0002

DCR Data Resource Center for Child and Adolescent Health FAQ (n.d.). http://childhealthdata.org/help/faq\#About1

Flores, G., Olson, L., \& Tomany-Korman, S. C. (2005). Racial and Ethnic Disparities in Early Childhood Health and Health Care. Pediatrics, 115, e183-e193.

https://doi.org/10.1542/peds.2004-1474

Francis, L., DePriest, K., Wilson, M., \& Gross, D. (2018). Child Poverty, Toxic Stress, and Social Determinants of Health: Screening and Care Coordination. Online Journal of Issues in Nursing, 23, 2. 
Hart, B., \& Risley, T. R. (1995). Meaningful Differences in the Everyday Experience of Young American Children. Baltimore, MD: Paul H Brookes Publishing.

Hertzman, C. (2010). Framework for the Social Determinants of Early Child Development. In R. E. Tremblay, M. Boivin, \& R. V. Peters (Eds.), Encyclopedia on Early Childhood Development.

http://www.child-encyclopedia.com/importance-early-childhood-development/accordi ng-experts/framework-social-determinants-early-child

Moore, T. G., McDonald, M., Carlon, L., \& O’Rourke, K. (2015). Early Childhood Development and the Social Determinants of Health Inequities. Health Promotion International, 30, 102-115. https://doi.org/10.1093/heapro/dav031

NSCH National Survey of Children's Health (n.d.). National Survey of Children's Health (NSCH), 2011/12 Fast Facts about the Survey. http://childhealthdata.org/learn/NSCH/FAQ

Phillips, D. A., \& Shonkoff, J. P. (2000). From Neurons to Neighborhoods: The Science of Early Childhood Development. Washington DC: National Academies Press.

Smedley, B. D., Stith, A. Y., \& Nelson, A. R. (2003). Unequal Treatment: Confronting Racial and Ethnic Disparities in Health Care. Institute of Medicine, Committee on Understanding and Eliminating Racial and Ethnic Disparities in Health Care.

Tolliver, R. (2010). The Connection between Health Disparities and the Social Determinants of Health in Early Childhood. Health, 800, 886-7689.

Woolf, S. H., \& Braveman, P. (2011). Where Health Disparities Begin: The Role of Social and Economic Determinants-And Why Current Policies May Make Matters Worse. Health Affairs, 30, 1852-1859. https://doi.org/10.1377/hlthaff.2011.0685 